\title{
Estandarización de una PCR anidada para la identificación de Lawsonia intracellularis en porcinos
}

\author{
Ángela Jiménez ${ }^{\star}, \mathrm{MVZ}_{1}$, Stella Cortez, $\mathrm{MVZ}_{1}$, Luz Zoraya Duarte, $\mathrm{MVZ}_{1}$, Marcela Martínez, $\mathrm{MVZ}_{1}$, \\ Silva Yuliana Flórez, $\mathrm{MVZ}_{1}$, Carolina Méndez, $\mathrm{MVZ}_{1}$, Marcel Granados, $\mathrm{MVZ}_{1}$, Anderson Villamizar, $\mathrm{MVZ}_{1}$
}

${ }^{1}$ Facultad de Medicina Veterinaria y Zootecnia, Universidad Cooperativa de Colombia, Bucaramanga, Colombia

Recibido: 15 de enero del 2014. Aprobado: 30 de mayo del 2014.

*Autor de correspondencia: Ángela Jiménez. Universidad Cooperativa de Colombia, Bucaramanga, Colombia, calle 30A \# 33-51. Teléfono: (+57) 7 6854500, ext. 7072. Correo electrónico: angela.jimenez@campusucc.edu.co

Cómo citar este artículo: Jiménez A, Cortez S, Duarte LZ, Martínez M, Flórez SY, Méndez C, et al. Estandarización de una PCR anidada para la identificación de Lawsonia intracellularis en porcinos. Spei Domus. 2014;10(20):23-29. doi: http://dx.doi.org/10.16925/sp.v10i20.887

Resumen. Introducción: se estandarizó una técnica de Reacción en Cadena de la Polimerasa PCR anidada para el diagnóstico de la enteropatía proliferativa porcina causada por la bacteria Lawsonia intracellularis. Métodos: la técnica se basó en la amplificación de una región de 270 pb del gen 16s ARNr de Lawsonia intracellularis; para tal fin, se extrajo el ADN de la bacteria mediante el kit Purelink Genomic, Invitrogen ${ }^{\circledR}$, a partir de 100 muestras de íleon de porcinos provenientes del área metropolitana de Bucaramanga (Santander). Los ADN fueron cuantificados por fluorometría y ajustados a una concentración de $20 \mathrm{ng} / \mu \mathrm{L}$. Se llevó a cabo una primera amplificación de la porción de 319 pb del gen 16s ARN con los iniciadores externos: 5'-TAT GGC TGT CAA ACA CTC CG-3' Y 5'-TGA AGG TAT TGG TAT TCT CC-3'. El producto de esta primera amplificación se usó de molde para una segunda reacción, en la que se amplificó una porción interna de $270 \mathrm{pb}$ del gen 16s ARN de L. intracellularis, empleando los iniciadores internos específicos: 5'-TTA CAG GTG AAG TTA TTG GG-3' Y 5'-CTT TCT CAT GTC CCA TAA GC-3'. Las condiciones óptimas para las PCR tanto con los iniciadores internos como con los externos incluyeron: $2,5 \mu \mathrm{M}$ de $\mathrm{MgCl}_{2} ; 0,15 \mu \mathrm{M}$ de cada dNTP; $1 \mathrm{x}$ de Buffer de reacción; 0,8 $\mu \mathrm{M}$ de cada iniciador; y 2,5 U de Taq polimerasa. Como control positivo tanto en la extracción de ADN como en las PCR, se empleó ADN bacteriano extraído de la vacuna Enterisol $^{\circledR}$ (Boheringer Ingelheim ${ }^{\circledR}$ ). Resultados: las temperaturas óptimas de anillamiento para la PCR simple y anidada fueron de 50 y $55^{\circ} \mathrm{C}$, respectivamente. El límite de detección de la técnica fue de $5 \mathrm{fg}$. Conclusiones: la técnica no evidenció reacción cruzada con Esquerichia coli, ni con Salmonella typhimurium, bacterias con cuadros clínicos semejantes.

Palabras clave: cerdos, diagnóstico molecular, ileítis.

PCR Standardization to Identify Lawsonia intracellularis in Pigs

Abstract. Introduction: the nested Polymerase Chain Reaction (PCR) technique has been standardized for the diagnosis of porcine proliferative enteropathy caused by Lawsonia intracellularis. Methods: such technique was based upon amplifying a region of $270 \mathrm{pb}$ of the $16 \mathrm{~s}$ ARNr gene of the Lawsonia intracellularis. For such purposes, a DNA sample was taken from the bacteria with a Purelink Genomic kit, Invitrogen ${ }^{\otimes}$, from 100 samples of porcine ileum of the metropolitan area of Bucaramanga (Santander). The DNA samples were quantified with fluorometry and adjusted to $20 \mathrm{ng} / \mu \mathrm{L}$ concentration. The first amplification of the $319 \mathrm{pb}$ part of the $16 \mathrm{~s}$ gene was completed with the external initiators: 5'-TAT GGC TGT CAA ACA CTC CG-3' and 5'-TGA AGG TAT TGG TAT TCT CC-3'. The result of this first amplification was used as a pattern for the second reaction, where the internal part of $270 \mathrm{pb}$ of the 16s ARN gene of $L$. intracellularis was amplified using the specific internal initiators: 5'-TTA CAG GTG AAG TTA TTG GG-3' and 5'-CTT TCT CAT GTC CCA TAA GC-3'. The optimal conditions for the PCR for both internal and external initiators included 2,5 $\mu \mathrm{M} \mathrm{de} \mathrm{MgCl}_{2} ; 0,15 \mu \mathrm{M}$ of each dNTP; $1 \mathrm{x}$ of reaction buffer; 0,8 $\mu \mathrm{M}$ of each initiator; and 2,5 $\mathrm{U}$ of Taq polymerase. As a positive control for the taken DNA samples and the PCR, the bacterial DNA taken from Enterisol ${ }^{\circledR}$ (Boheringer Ingelheim $^{\circledast}$ ) was used. Results: optimal temperatures of annealing for the simple and nested PCR were 50 and $55^{\circ} \mathrm{C}$, respectively. The detection limit of the technique was $5 \mathrm{fg}$. Conclusions: no cross reactions were found with Esquerichia coli, or with Salmonella typhimurium, which are bacteria with similar clinical conditions.

Keywords: pigs, molecular diagnosis, ileitis.

\section{Estandardização de Uma PCR aninhada (nested PCR) para a identificação de Lawsonia intracellularis em suínos}

Resumo. Introdução: foi estandardizada uma técnica de Reação em Cadeia da Polimerase PCR aninhada para o diagnóstico da enteropatia proliferativa suína causada pela bactéria Lawsonia intracellularis. Métodos: a técnica foi baseada na amplificação de uma região de $270 \mathrm{pb}$ do gene 16s ARNr de Lawsonia intracellularis; para esse fim, foi extraído o ADN 
da bactéria mediante o kit Purelink Genomic, Invitrogen ${ }^{\oplus}$, a partir de 100 amostras de íleo de suínos provenientes da zona metropolitana da cidade de Bucaramanga (Santander, Colômbia). Os ADN foram quantificados por fluorometria e ajustados a uma concentração de $20 \mathrm{ng} / \mu \mathrm{L}$. foi feita uma primeira amplificação da porção de $319 \mathrm{pb}$ do gene $16 \mathrm{~s}$ ARN com os iniciadores externos: 5'-TAT GGC TGT CAA ACA CTC CG-3' E 5'-TGA AGG TAT TGG TAT TCT CC-3' O produto desta primeira amplificação foi utilizada como molde para uma segunda reação, na qual foi amplificada uma porção interna de $270 \mathrm{pb}$ do gene $16 \mathrm{~s}$ ARN de $L$. intracellularis, usando os iniciadores internos específicos: 5'-TTA CAG GTG AAG TTA TTG GG-3' e 5'-CTT TCT CAT GTC CCA TAA GC-3'. As condições óptimas para as PCR,

\section{Introducción}

La industria porcina se enfrenta constantemente a enfermedades gastrointestinales, que son responsables de generar pérdidas económicas tanto en las fases de destete como de finalización. En tiempos recientes, se ha trabajado en las características genotípicas de virulencia de los patógenos, así como en las posibles medidas profilácticas para evitar los efectos lesivos resultantes de la invasión y replicación directa sobre la mucosa intestinal de bacterias como Lawsonia intracellularis [1].

L. intracellularis es una bacteria intracelular que causa enteritis proliferativa porcina (EPP), infección reportada en América con prevalencias superiores al $30 \%$. El impacto económico generado por entidades gastrointestinales del tipo de la ileítis porcina puede ser importante en países como Brasil, Chile, Argentina, Colombia, Paraguay y Venezuela; considerados los de mayor producción oficial en Suramérica [2, 3, 4]. En Colombia, por técnicas serológicas y tinción de plata, se describen prevalencias del $20-87 \%$, principalmente en Antioquia y Cundinamarca. En la industria porcícola santandereana no existen reportes que aproximen una información actual sobre la situación de la EPP desencadenada por esta bacteria. La presente investigación optimizó una técnica de PCR anidada, útil para el futuro diagnóstico y conocimiento de la situación epidemiológica de la $L$. intracellularis en el departamento de Santander.

\section{Materiales y métodos}

\section{Muestras de íleon porcino}

Se tomaron 100 muestras de tejido (25-30 mg de íleon porcino) provenientes de porcinos de diferentes municipios del área metropolitana de Bucaramanga tanto com os iniciadores internos quanto com os externos incluíram: 2,5 $\mu$ M de $\operatorname{MgCl}_{2} ; 0,15 \mu$ de cada dNTP; 1 X de Buffer de reação; 0,8 $\mu$ M de cada iniciador; e 2,5 u de Taq polimerase. Como controle positivo tanto na extração de ADN quanto nas PCR, foi empregado ADN bacteriano extraído da vacina Enterisol ${ }^{\circledR}$ (Boheringer Ingelheim $\left.{ }^{\circledR}\right)$. Resultados: as temperaturas óptimas de anilhagem para a PCR simples e aninhada foram de 50 e $55^{\circ} \mathrm{C}$, respectivamente. O limite de detecção da técnica foi de 5 fg. Conclução: a técnica não evidenciou reação cruzada com Esquerichia coli, nem com Salmonella typhimurium, bactérias com quadros clínicos similares.

Palavras-chave: porcos, diagnóstico molecular, ileitis.

(Lebrija, Mesa de los Santos, Girón, Piedecuesta). Las muestras fueron tomadas a partir de animales que presentaron sintomatología gastrointestinal (pérdida de peso, diarrea, anorexia, bajo índice de conversión, apatía, etc.). Cada muestra fue almacenada en buffer TE $1 \mathrm{x}$ a $-60{ }^{\circ} \mathrm{C}$.

\section{Extracción y cuantificación de ADN}

A cada una de las muestras de íleon se le extrajo el ADN mediante el kit de extracción Purelinktm Genomic DNA Mini kit Invitrogen ${ }^{\oplus}$. Los ADN fueron cuantificados mediante fluorometría con el Qubit Fluorometer Invitrogen $^{\oplus}$, y ajustados a una concentración de $20 \mathrm{ng} / \mu \mathrm{L}$ en buffer TE1X. Para verificar la calidad del ADN extraído, se llevó a cabo una electroforesis en gel de agarosa $\left(\right.$ Merck $\left.^{\oplus}\right)$ al $1,5 \%$, por una hora a 74 voltios, empleando un patrón de peso molecular de 100 pb Promega $^{\circledR}$ y como colorante, Az Vision Amresco ${ }^{\oplus}$; los geles de agarosa fueron visualizados mediante transiluminador UV.

\section{Estandarización de la PCR}

\section{Control positivo}

Se extrajo ADN de la bacteria L. intracellularis contenida en la vacuna Enterisol ${ }^{\circledR}$ (Boheringer Ingelheim ${ }^{\circledR}$ ), mediante el mismo kit empleado para los tejidos de íleon porcino. Asimismo, fueron inoculadas porciones de $25 \mathrm{mg}$ de íleon porcino con $200 \mu \mathrm{L}$ de vacuna completa, y a dicha solución se le realizó el mismo proceso de extracción.

Ambos controles positivos, tanto ADN proveniente de vacuna como ADN proveniente de íleon porcino inoculado con vacuna, fueron cuantificados por fluorometría y su calidad fue evaluada mediante electroforesis 
en geles de agarosa al 1,5\%, bajo las condiciones previamente descritas.

\section{Iniciadores}

A partir de los controles positivos se amplificó la porción de $319 \mathrm{pb}$ del gen 16s ARNr con los iniciadores externos: 5'-TAT GGC TGT CAA ACA CTC CG-3' y 5'-TGA AGG TAT TGG TAT TCT CC-3. El producto de esta primera amplificación se usó de molde para una segunda reacción, en la que se amplificó una porción interna de $270 \mathrm{pb}$ del gen 16 s ARN de L. intracellularis, empleando los iniciadores internos específicos: 5'-TTA CAG GTG AAG TTA TTG GG3 ' y 5'-CTT TCT CAT GTC CCA TAA GC-3' [5].

\section{Condiciones de la PCR}

Las condiciones de amplificación fueron optimizadas con los controles positivos. Para esto, se evaluaron gradientes de temperatura de $50-55^{\circ} \mathrm{C}$ tanto para la PCR simple como para la anidada. Para ambas PCR, se preparó una mezcla de $25 \mu \mathrm{L}$ con $2,5 \mu \mathrm{M}$ de $\mathrm{MgCl}_{2} ; 0,15 \mu \mathrm{M}$ de cada dNTP; 1x de Buffer de reacción; 0,8 $\mu \mathrm{M}$ de cada iniciador; y 2,5 U de Taq polimerasa (Corpogen ${ }^{\circledR}$ ). Como ADN molde se usaron 100 ng de ADN en la primera reacción, y en la segunda se emplearon $3 \mu \mathrm{L}$ del primer amplificado $[5,6,7]$.

Las tablas 1 y 2 describen las temperaturas y los ciclos programados en el termociclador para la PCR simple y anidada, respectivamente.

Tabla 1. Programación del termociclador para la PCR simple

\begin{tabular}{|l|c|c|c|}
\hline \multicolumn{1}{|c|}{ Termociclador } & Temperatura & Tiempo & Ciclos \\
\cline { 1 - 3 } 1. Precalentamiento & $95^{\circ} \mathrm{C}$ & 3 minutos & 1 \\
\cline { 1 - 3 } 2. Desnaturalización & $95^{\circ} \mathrm{C}$ & 30 segundos & \multirow{2}{*}{30} \\
\cline { 1 - 3 } 3. Hibridación o asociación de primers externos & $55^{\circ} \mathrm{C}$ & 60 segundos & \\
\cline { 1 - 3 } 4. Extensión & $72^{\circ} \mathrm{C}$ & 30 segundos & \\
\hline Ir al paso 2 (30 veces) & & & 1 \\
\hline Extensión final & $72^{\circ} \mathrm{C}$ & 3 minutos & \\
\hline
\end{tabular}

Fuente: elaboración propia

Tabla 2. Programación del termociclador para la PCR anidada

\begin{tabular}{|l|c|c|c|}
\hline \multicolumn{1}{|c|}{ Termociclador } & Temperatura & Tiempo & Ciclos \\
\cline { 1 - 3 } 1. Precalentamiento & $95^{\circ} \mathrm{C}$ & 3 minutos & 1 \\
\cline { 1 - 3 } 2. Desnaturalización & $95^{\circ} \mathrm{C}$ & 30 segundos & \multirow{2}{*}{30} \\
\cline { 1 - 3 } 3. Hibridación o asociación de primers externos & $50^{\circ} \mathrm{C}$ & 60 segundos & \\
\cline { 1 - 3 } 4. Extensión & $72^{\circ} \mathrm{C}$ & 30 segundos & \\
\hline Ir al paso 2 (30 veces) & & & 3 minutos \\
\hline Extensión final & $72^{\circ} \mathrm{C}$ & & \\
\hline
\end{tabular}

Fuente: elaboración propia

Todos los productos de las PCR anidadas fueron visualizados por electroforesis en gel de agarosa al 1,5\%, mezclando $7 \mu \mathrm{L}$ de amplificado con $3 \mu \mathrm{L}$ de colorante E-Z Vision de Amresco ${ }^{\oplus}$, en buffer TAE 1x a 85 voltios, durante una hora. Se empleó un patrón de peso molecular de $100 \mathrm{pb}$ de Promega ${ }^{\oplus}$. Los geles se visualizaron en transiluminador Uv.

\section{Límite de detección de la técnica}

$\mathrm{Al}$ ADN cromosomal bacteriano (control positivo) previamente cuantificado se le hicieron ocho diluciones en base diez por duplicado, con el fin de determinar la cantidad mínima de detección de ADN de la bacteria. A todas las diluciones se les realizó la PCR por duplicado bajo las condiciones descritas. 
Asimismo, cada una de las diluciones de ADN bacteriano fue mezclada en partes iguales con ADN de tejido negativo en $L$. intracellularis a concentración constante (ADN felino extraído por la misma metodología y previamente cuantificado), con el objetivo de conocer el límite de detección real de la técnica. A todas las diluciones se les realizó la PCR por duplicado.

\section{Evaluación de reacción cruzada}

Para evaluar la especificidad de la técnica, se llevó a cabo el análisis de reacción cruzada con otros agentes responsables de enfermedades entéricas en cerdos y que producen cuadros clínicos similares al de la enteropatía proliferativa porcina (EPP). Se prepararon soluciones bacterianas de Escherichia coli ATCC 25922 y de Salmonella typhimurium ATCC 14028 en agua estéril a concentración de $100 \mathrm{mg} / \mu \mathrm{L}$. A partir de cada solución, se extrajo el ADN mediante el kit PurelinkTM Genomic DNA Mini kit Invitrogen ${ }^{\oplus}$. Los extractos fueron diluidos a concentración de $20 \mathrm{ng} / \mu \mathrm{L}$ y se les realizó PCR bajo las condiciones estandarizadas para L. intracellularis.

\section{Evaluación de la PCR en muestras de campo}

Una vez optimizadas las condiciones de la PCR a partir de los controles positivos, esta fue empleada para la identificación de la bacteria en las 100 muestras de campo provenientes de porcinos del área metropolitana de Bucaramanga. En cada reacción de PCR simple, se emplearon dos controles negativos: agua como sustituto del ADN molde y mezcla de sólo reactivos sin agua y sin ADN molde. Para la segunda reacción de amplificación, se empleó agua como sustituto del ADN molde, mezcla de sólo reactivos sin agua y sin ADN molde, y de los controles negativos de la primera amplificación. Los controles positivos fueron los previamente estandarizados.

\section{Resultados}

\section{Extracción y cuantificación de ADN}

De todas las 100 muestras de tejido porcino se obtuvo ADN cromosomal. Se encontraron concentraciones de ADN entre 10 y $800 \mathrm{mg} / \mu \mathrm{L}$. La figura 1 muestra algunas de las bandas definidas de ADN cromosomal que indican la calidad de los extractos obtenidos.

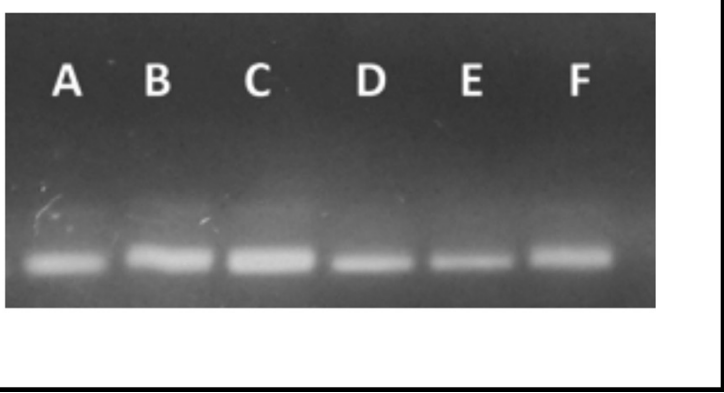

Figura 1. Electroforesis en gel de agarosa al 1,5\%

${ }^{*}$ Carril A-F: ADN cromosomales extraídos con kit Purelink Genomic DNA Mini kit Invitrogen ${ }^{\otimes}$, a partir de íleon de porcinos con signos gastrointestinales

Fuente: elaboración propia

\section{Estandarización de la PCR}

\section{Controles positivos}

A partir del ADN de la vacuna Enterisolø y del ADN de íleon porcino inoculado con la vacuna, se obtuvo un amplificado de $270 \mathrm{pb}$ visualizado por electroforesis en gel de agarosa al 1,5\% (figura 2 ).

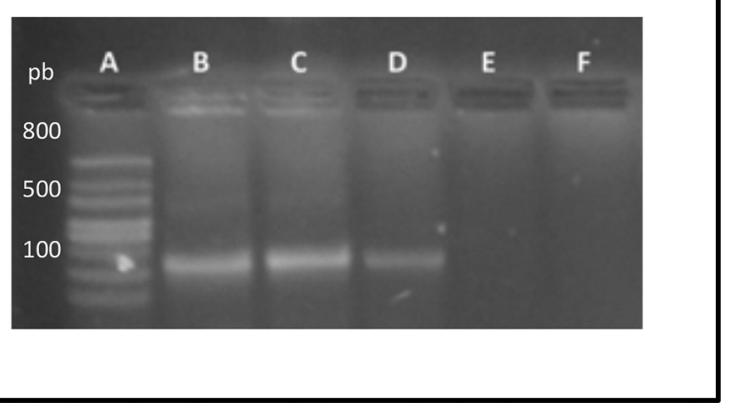

Figura 2. Electroforesis en gel de agarosa al 1,5\%

${ }^{*}$ Carril A: patrón de peso molecular de 100 pb Promega ${ }^{\oplus}$; carril B: control positivo a partir de vacuna Enterisol ${ }^{\circledR}$ Ileítis (Boheringer Ingelheim ${ }^{\circledR}$ ); carril c: duplicado del control positivo; carril D: control positivo de tejido inoculado con vacuna Enterisolø Ileítis (Boheringer Ingelheim»); carriles E y F: controles negativos

Fuente: elaboración propia

\section{Condiciones de la PCR}

Se determinaron como temperaturas óptimas de anillamiento: 50 y $55^{\circ} \mathrm{C}$ para las PCR simples y anidadas, respectivamente. Las condiciones óptimas para las PCR tanto con los iniciadores internos como con los externos incluyeron: $2,5 \mu \mathrm{M}$ de $\mathrm{MgCl}_{2} ; 0,15 \mu \mathrm{M}$ de cada dNTP; $1 \mathrm{x}$ de Buffer de reacción; 0,8 $\mu \mathrm{M}$ de cada iniciador; $\mathrm{y}$ 2,5 u de Taq polimerasa. 
La figura 3 muestra un control positivo y una muestra positiva, a temperatura de $55^{\circ} \mathrm{C}$ de la PCR anidada en gel de agarosa al 1,5\%.

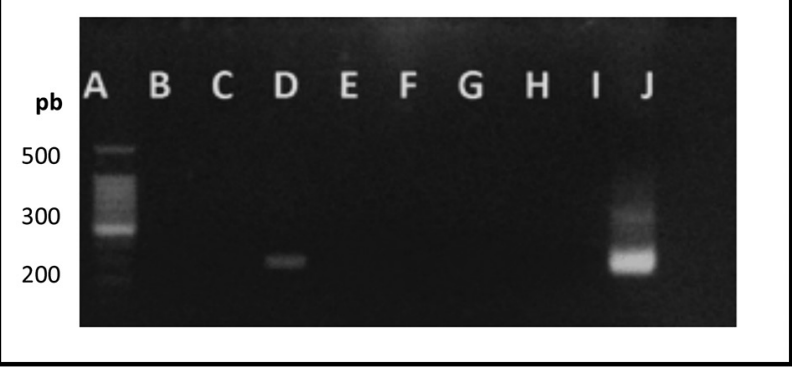

Figura 3. Electroforesis en gel de agarosa al 1,5\%

${ }^{*}$ Carril A: patrón de peso molecular de $100 \mathrm{pb}$ Promega ${ }^{\otimes}$; carriles в у C: muestras negativas; carril D: muestra positiva; carriles E-I: muestras negativas; carril J: control positivo

Fuente: elaboración propia

\section{Límite de detección de la técnica}

La técnica evidenció un límite de detección muy alto (5 fg) para el gen 16s ARNr (figura 4).

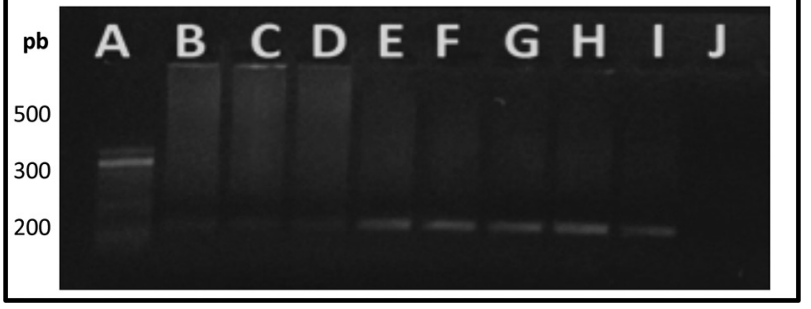

Figura 4. Electroforesis en gel de agarosa al 1,5\%

${ }^{*}$ Carril A: patrón de peso molecular de 50 pb Promegaब; carril B: 50 ng de ADN de L, Intracellularis; carril c: 5 ng de ADN; carril D: 0,5 ng de ADN; carril E: 50 pg de ADN; carril F: 5 pg de ADN; carril g: 0,5 pg de ADN; carril H: $50 \mathrm{fg}$ de ADN; carril I: $5 \mathrm{fg}$ de ADN de $L$, Intracellularis; carril $j: 0,5 \mathrm{fg}$ de ADN

Fuente: elaboración propia

\section{Evaluación de la reacción cruzada}

La figura 5 evidencia la no existencia de reacción cruzada de la PCR estandarizada con Escherichia coli ATCC y Salmonella tiphymurium ATCC, agentes causales de enfermedades del tracto gastrointestinal y de signología entérica similar a la de la enteropatía proliferativa porcina.

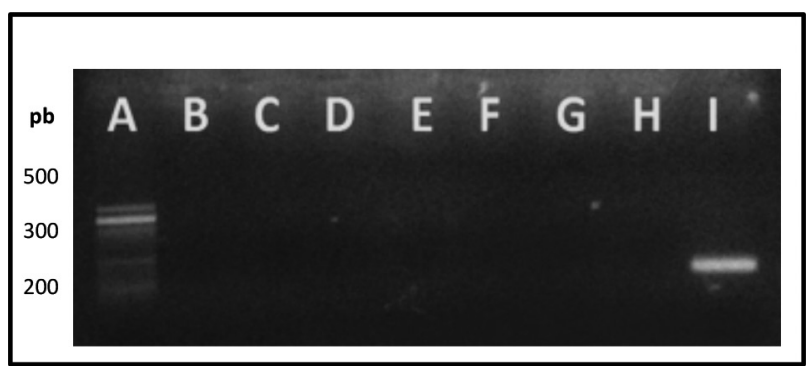

Figura 5. Electroforesis en gel de agarosa al 1,5\%

${ }^{*}$ Carril A: patrón de peso molecular de $100 \mathrm{pb}$ Promega ${ }^{\oplus}$; carriles в у C: ADN no amplificado de Salmonella typhimurium; carriles D y E: ADN no amplificado de Escherichia coli; carriles F-H: controles negativos; carril I: control positivo

Fuente: elaboración propia

Evaluación de la PCR estandarizada en muestras de campo

De las 100 muestras de íleon de cerdos que murieron a causa de enfermedades gastrointestinales y que presentaban síntomas como pérdida de peso, diarrea y anorexia, el 56\% resultaron positivas.

\section{Discusión}

Esta investigación estandarizó una técnica de PCR anidada para la amplificación de la porción de 270 pb del gen 16s ARNr de L. intracellularis, agente causal de la enteritis proliferativa porcina y responsable de importantes pérdidas económicas en el sector porcícola [8]-[10]. La técnica permitió confirmar la presencia de L. intracellularis en las explotaciones del área metropolitana de Bucaramanga. El 56\% de las muestras resultaron positivas por la prueba de PCR anidada estandarizada.

La misma técnica que se optimizó en este estudio fue descrita por diversos autores [5], [11]-[13], y fue reseñada desde su desarrollo inicial por Jones et al., en 1993 [7], quienes reportaron positividades del orden del 25 al 65\% en países como Alemania y Polonia [11]. El límite de detección de 5 fg y la no presencia de reacción cruzada con microorganismos relacionados hacen de esta técnica una herramienta de elección para la detección temprana de animales positivos en granja.

Nuestros resultados concuerdan con otros reportes [5], [7], [11]-[13], que documentan una alta especificidad y sensibilidad de la técnica empleando los mismos iniciadores e iguales condiciones de amplificación. Jones et al., que optimizaron la técnica por 
primera vez, reportaron una sensibilidad muy alta del orden de $10^{1}$ microorganismos en mucosa intestinal en presencia de ADN heterólogo [7]. Los mismos autores evaluaron la especificidad de la técnica por hibridación in situ y aplicando la PCR anidada a diferentes microorganismos relacionados.

Los iniciadores y las condiciones de amplificación empleados en este estudio habían sido evaluados previamente en ADN intestinal porcino y en ADN de: Brachyspira sp.; c. hyointestinalis; c. mucosalis; c. coli; C.jejuni; c. fetus; c. concisus; c. laridis; c. cinaedi; c. fennelliae; c. cryaerophila; c. sputorum; Cl. Perfringens tipos A, B y C; s. typhimurium; y E. coli. [12], lo cual comprobó la no existencia de reacción cruzada.

La confiabilidad de la técnica estandarizada se sustenta en varios hechos: el tamaño de la muestra (100) proveniente de animales con cuadro clínico gastrointestinal, la no existencia de reacción cruzada, la alta sensibilidad analítica, y el comportamiento consistente de controles positivos y controles negativos, de acuerdo con lo esperado.

La positividad del $56 \%$ evidenciada por la PCR anidada estandarizada sugiere la necesidad de llevar a cabo estudios epidemiológicos que determinen parámetros de frecuencia de la infección y su asociación con factores de riesgo, con miras a establecer programas de prevención y control en el departamento de Santander.

Debido a que la enteropatía proliferativa porcina desencadenada por la bacteria Lawsonia intracellularis genera alta incidencia de cuadros subclínicos, principalmente en animales jóvenes, se hace indispensable la utilización de técnicas moleculares como la optimizada en este estudio, para un diagnóstico certero y a tiempo que permita la prevención de pérdidas económicas en granja.

\section{Referencias}

[1] Friedman M, Bednář V, Klimeš J, Smola J, Mrlík V, Literák I. Lawsonia intracellularis in Rodents from Pig Farms with the Occurrence of Porcine Proliferative Enteropathy. Lett Appl Microbiol. 2008; 47(2):117-21.

[2] Jensen TK, Vigre H, Sorensen V, Moller K. Naturally Acquired Lawsonia Intracellularis Infection in Pigs Studied from Weaning to Slaughter by Indirect Inmunoflrescence Antibody Test and
Polymerase Chain Reaction on Faeces. Res Vet Sci. 2005; 79(2):93-8.

[3] Mogollón G, Rincón M, Arbeláez G, Ruiz S, De La Rosa S, Lara AM. Aplicación de las técnicas moleculares para el diagnóstico de las enfermedades porcinas en Colombia. ICA Informa. 2002; 28(1):30-6.

[4] Ladining A, Sommerfeld I, Weissenbock H. Comparative Evaluation of Diagnostic Methods for Lawsonia intracellularis Infection in Pigs, with Emphasis on Cases Lacking Characteristic Lesions. J Comp Path. 2009; 140(2-3):140-8.

[5] Jacobson M, Aspan A, Königsson MH, Segerstad C, Wallgren P, Fellström C, et al. Routine Diagnostics of Lawsonia intracellularis Performed by PCR, Serological and Post Mortem Examination, with Special Emphasis on Sample Preparation Methods for PCR. Vet Microbiol. 2004; 102(3-4):189-201.

[6] Pusterla N, Mapes S, Rejmanek D, Gebhart C. Detection of Lawsonia intracellularis by Real-Time PCR in the Feces of Free-Living Animals from Equine Farms with Documented Occurrence of Equine Proliferative Enteropathy. J Wildl Dis. 2008; 44(4):992-8.

[7] Jones GF, Ward GE, Murtaugh MP, Lin G, Gebhart CJ. Enhanced Detection of Intracellular Organism of swine Proliferative Enteritis, Ileal Symbiont Intracellularis, in Feces by Polymerase Chain Reaction. J Clin Microbiol. 1993; 31(10):2611-5.

[8] Boutrup TS, Boesen HT, Boye M, Agerholm JS, Jensen TK. Early Pathogenesis in Porcine Proliferative Enteropathy Caused by Lawsonia intracellularis. J Comp Pathol. 2010; 143(2-3):101-9.

[9] McOrist S, Smith SH, Green LE. Estimate of Direct Financial Losses Due to Porcine Proliferative Enteropathy. Vet Rec. 1997; 140(22):579-81.

[10] Rubio NP. La epidemiología y la repercusión económica de Lawsonia intracellularis. Documento presentado en: Simposio Europeo sobre Enterisol ${ }^{\oplus}$ Ileítis. 2005 oct 13-15; Barcelona.

[11] Brandt D, Kaim U, Baumgartner W, Wendt M. Evaluation of Lawsonia intracellularis Infection in a Group of Pigs in a Subclinically Affected Herd from Weaning to Slaughter. Vet Microbiol. 2010; 146(3-4):361-5. 
[12] Jacobson M. Enteric Diseases in Pigs from Weaning to Slaughter [tesis doctoral]. [Upsala]: Swedish University of Agricultural Sciences; 2003.
[13] Jacobson M, Aspan A, Nordengrahn A, Lindberg CM, Wallgren P. Monitoring of Lawsonia intracellularis in Breeding Herd Gilts. Vet Microbiol. 2010; 142(3-4):317-22. 